\title{
História da Educação na região Oeste do Paraná: a implantação da Escola Rural de Dois Irmãos (1953-1959)
}

\author{
History of Education in West Region of Parana: the implementation of the \\ Dois Irmãos Rural School (1953-1959)
}

\author{
Rodrigo Pinto de Andrade \\ Doutor em Educação \\ Universidade Estadual de Maringá - UEM \\ Maringá, Paraná-Brasil \\ rodrigoandrade.uem@gmail.com \\ Cézar de Alencar Arnaut de Toledo \\ Doutor em Educação \\ Universidade Estadual de Maringá - UEM \\ Maringá, Paraná-Brasil \\ caatoledo@uem.br \\ Francielle Aparecida Garuti de Andrade \\ Mestre em Educação \\ Universidade Estadual de Maringá - UEM \\ Maringá, Paraná-Brasil \\ garutiandrade@gmail.com
}

\begin{abstract}
Resumo: Este texto analisa a história da implantação da Escola Rural de Dois Irmãos, uma das primeiras instituições escolares construída e mantida pelo poder público na região Oeste do Paraná. A escola foi fundada em 1953 visando atender aos filhos dos trabalhadores rurais que residiam na localidade. Trata-se de um estudo histórico e documental. Sua realização se deu por meio da análise de documentos que descrevem o processo de migração, colonização e escolarização do oeste paranaense, bem como a trajetória histórica desta escola. Para a efetivação da pesquisa foram utilizadas as seguintes fontes: livros-ata de exames finais; livro de registros dos primeiros anos de funcionamento da escola; diários de classe; ata de fundação; decretos e leis municipais; jornais da época da fundação da instituição e materiais iconográficos das atividades escolares na década de 1950. Os dados revelados pelas fontes foram analisados à luz da literatura sobre instituições escolares e relacionados às condições sociais do contexto político/econômico em que foram produzidos.
\end{abstract}

Palavras-chave: História da Educação. Oeste Paranaense. Instituições Escolares. Escola Rural de Dois Irmãos.

\begin{abstract}
This text analyzes the history of the implantation of the Dois Irmãos Rural School, one of the first educational institutions, built and maintained by the government in the West region of Parana. The school was founded in 1953 aiming at meeting the children of rural workers who lived in that locality. It is a historical and documentary study. This achievement was through the analysis of documents that describe the process of migration, colonization and schooling of the region, as well as the school's historical trajectory. For the realization of the research were used the following sources: books of final exams; book of records of the early years of operation of the school; class diaries; minutes of foundation; decrees and municipal laws; newspapers of the time of the foundation of the institution; iconographic materials of school activities in the 1950 s. The data revealed by the sources were analyzed on the light of literature about educational institutions and related to the social conditions of the politicaleconomic context in which they were produced.
\end{abstract}

Keywords: History of Education. West Paraná region. Educational Institutions.Dois Irmãos Rural School.

Cite como

(ABNT NBR 6023:2018)

ANDRADE, Rodrigo Pinto de; TOLEDO, Cézar de Alencar Arnaut de; ANDRADE, Francielle Aparecida Garuti de. História da Educação na região Oeste do Paraná: a implantação da Escola Rural de Dois Irmãos (1953-1959). Dialogia, São Paulo, n. 37, p. 1-15, e19746, jan./abr. 2021. Disponível em: https://doi.org/10.5585/dialogia.n37.19746.

American Psychological Association (APA)

Andrade, R. P., Toledo, C. de. A. A., \& Andrade, F. A. G. (2021, jan./abr.). História da Educação na região Oeste do Paraná: a implantação da Escola Rural de Dois Irmãos (1953-1959). Dialogia, São Paulo, 37, p. 1-15, e19746.

https://doi.org/10.5585/dialogia.n37.19746. 
ANDRADE, Rodrigo Pinto de; TOLEDO, Cézar de Alencar Arnaut de; ANDRADE, Francielle Aparecida Garuti de. História da Educação na região Oeste do Paraná: a implantação da Escola Rural de Dois Irmãos (1953-1959)

Introdução

Trata-se de uma pesquisa documental na área da História da Educação regional e tem como objeto de análise a Escola Rural de Dois Irmãos, instituição escolar pública, fundada em 1953 com o propósito de atender aos filhos dos trabalhadores da zona rural do distrito de Dois Irmãos, no oeste paranaense. A história da educação no Oeste do Paraná esteve diretamente relacionada ao movimento migratório que aconteceu na região, a partir da segunda metade da década de 1940, sob a direção de empresas colonizadoras nacionais, de capital privado. Neste contexto, as instituições educativas foram gestadas sempre a partir da realidade do interior dos núcleos de colonização, oferecendo um formato de educação muito peculiar, que aliava economia regional e educação.

Os primeiros migrantes chegaram ao Oeste do Paraná no final da década de 1940 e início de 1950, em sua maioria, eram oriundos de outros estados da região Sul, que vinham para a região em busca de oportunidade de trabalhar na terra, para isso, compravam pequenos lotes rurais para desenvolver a agricultura familiar de subsistência. Os núcleos urbanos eram criados e, ao redor deles, eram formados os povoados, localidades onde as famílias desenvolviam atividades agrícolas. Nesses locais, o poder público e a iniciativa privada se uniram para construir escolas, com o propósito de atender aos filhos dos colonos que se radicavam na região. Foi nesse contexto que a Escola Rural de Dois Irmãos foi criada (TOLEDO, 1957).

A instituição foi fundada no ano de 1953, no distrito de Dois Irmãos, no contexto da ampliação da oferta escolar para as localidades rurais do oeste paranaense e do desenvolvimento econômico da região. A área rural onde a escola foi construída era, à época, densamente povoada, pois estava recebendo grandes fluxos migratórios.

As atividades escolares tiveram início com um total de onze alunos, sob a regência do professor Armindo José Michels, que lecionou na instituição durante um período de seis anos. As aulas começaram no dia 14 de março de 1953 com a oferta do $1^{\circ}, 2^{\circ}$ e $3^{\circ}$ anos do Ensino Primário, no formato multisseriado. Segundo consta das atas de exames finais, de 1953 a 1959, a instituição funcionou com o nome de Escola Rural de Dois Irmãos, depois, mudou o nome para Escola Rural Municipal Princesa Isabel, passando a ofertar o Ensino Primário até o $5^{\circ}$ ano. Nesse período, a instituição esteve sob a supervisão da Secretaria Municipal de Toledo (ESCOLA RURAL DE DOIS IRMÃOS, 1953a; TOLEDO, 2010).

Atualmente a escola ainda mantém suas atividades no distrito de Dois Irmãos e oferece a modalidade de Ensino Fundamental, séries iniciais, com atendimento no período matutino, para um número de 36 alunos. No ano de 2023 a instituição comemorará seu $70^{\circ}$ aniversário de fundação. A população local considera a escola como um "patrimônio da comunidade", que 
exerceu um importante papel no processo de escolarização da região e na construção de uma cultura letrada (TOLEDO, 2011).

Para discutir a temática proposta, inicialmente será analisada as pesquisas sobre instituições escolares no contexto da História da Educação brasileira. Em seguida, será estudada a colonização e a escolarização da região Oeste do Paraná no período da criação da escola (1940-1960). Posteriormente será discutida a questão da educação rural no Brasil e no oeste paranaense. Por fim, será abordada a implantação da Escola Rural de Dois Irmãos, com uma particular ênfase na análise dos docentes e discentes da instituição.

A investigação foi realizada mediante a análise de documentos que descrevem o processo de criação, funcionamento e trajetória da escola em seus primeiros anos de atividades. Para a efetivação da pesquisa foram utilizadas fontes como: livros-ata de exames finais; livro de registros dos primeiros anos de funcionamento da escola; diários de classe; ata de fundação da escola; decretos e leis municipais; jornais da época da fundação da instituição; fotos dos alunos da primeira turma da escola na década de 1950. As fontes estão disponíveis nas seguintes localidades: acervo da Escola Rural Municipal Princesa Isabel; Museu Histórico Willy Barth e na Secretaria Municipal de Educação de Toledo, PR.

\section{Instituições escolares no contexto da História da Educação brasileira}

Atualmente, a temática da escola tem sido recorrente na área da História da Educação. Abordada sob as diversas perspectivas de informação e análise, a historiografia da escola vem sendo ampliada e renovada. Nos últimos anos multiplicaram-se as análises sobre a especificidade (cultura escolar, pedagogia, arquitetura, mobiliário, materiais didáticos, artefatos, disposição espacial); diversificaram-se estudos comparativos de amplitude territorial (local, regional, nacional, federal); foram revigorados parâmetros e perspectivas sobre mundialização e globalização do processo e do modelo didático-pedagógicos escolares (MAGALHÃES, 1998).

No Brasil, a análise da história das instituições escolares no Brasil, tem se firmado como uma Linha de Pesquisa no âmbito da História da Educação e constituído cada vez mais, num campo de investigação promissor. Um dos elementos motivadores para as investigações sobre essa área temática é a possibilidade de se escrever a História da Educação brasileira e regional sob um prisma diferente daquele que dá espaço apenas às narrativas emanadas de documentos oficiais. (ANDRADE, 2018; NOSELLA, BUFFA, 2009).

Essa linha de investigação tem se consolidado como uma proposta de pesquisa que visa à valorização das peculiaridades regionais, sem desconsiderar as dimensões nacionais; entende-se que 
ao analisar as características de uma determinada instituição, espacial e geograficamente determinada, nasce a possibilidade de conhecer o contexto histórico-político e social que a criou. Trata-se de um veio da pesquisa histórica que se ocupa em descrever seus protagonistas em suas ações, bem como, os diferentes momentos vividos pela instituição educativa, suas contradições, sua estrutura física, sua relação com as políticas educacionais, seu projeto pedagógico e outros temas que contribuem a compreensão do fenômeno histórico-educativo em sua totalidade (NOSELLA, BUFFA, 2009; SANFELICE, 2007).

A temática se insere no contexto da ampliação do número de novos objetos que têm sido analisados a partir de sua historicidade. Dentre os novos temas, destacam-se: instituições escolares, práticas educativas, políticas educacionais, educação rural, educação indígena, educação especial, educação a distância, entre outros. Apesar das dificuldades, devido à inexistência de repertórios de fontes organizadas, no Brasil, muitos historiadores da educação têm se lançado na tarefa de historiar a educação escolar por meio da construção de interpretações acerca das principais instituições educativas espalhadas pelas diversas regiões do país (SAVIANI, 2007).

A abordagem dos processos de formação e de evolução das instituições educativas constitui um domínio do conhecimento histórico em renovação no quadro da História da Educação, no qual novas formas de questionamento se cruzam com um alargamento das problemáticas e com uma sensibilidade acrescida à diversidade dos contextos e à especificidade dos modelos e das práticas educativas. A renovação da História da Educação adquiriu uma identidade epistemológica própria. Desde a década de 1960, a historiografia da educação tem evoluído por meio de revisões críticas e pela construção de conceitos e formas de proceder que permitem compreender e explicar os fenômenos educativos, especialmente nas instituições escolares. Essa renovação historiográfica das últimas décadas produziu importantes mudanças na área da História da Educação (MAGALHÃES, 2004; MAGALHÃES, 1999).

A história das instituições educativas faz parte deste processo de renovação e se constitui num desafio interdisciplinar. Nesse tipo de pesquisa, as análises sociológicas, organizacionais e curriculares compilam-se com o objetivo de uma reconstituição historiográfica de valor, pois se propõe a contextualizar a instituição pesquisada no cenário político, social, cultural e educacional em que ela foi implantada e desenvolveu suas atividades (MAGALHÃES, 1998).

O trabalho de analisar a história das instituições escolares, além de descrever a vida e os fatos que ocorreram no interior da escola, não fica preso apenas aos relatos históricos sobre seu dia a dia. Tais pesquisas devem levar o leitor à compreensão da totalidade histórica. Assim, historiar uma instituição educativa é investigar o que se passa ou se passou em seu interior, a partir da análise 


\section{Dialogia}

ANDRADE, Rodrigo Pinto de; TOLEDO, Cézar de Alencar Arnaut de; ANDRADE, Francielle Aparecida

Garuti de. História da Educação na região Oeste do Paraná: a implantação da Escola Rural de Dois Irmãos (1953-1959)

que envolve os vários atores participantes do processo educativo, à luz do contexto geral, pois o movimento em seu interior reflete, de maneira particular e elaborada, o movimento social no qual a instituição está inserida; a escola, portanto, deve ser analisada à luz de seu contexto histórico, social e político (SAVIANI, 2013; NOSELLA; BUFFA, 2009).

\section{Migração e escolarização na região oeste do Paraná (1940 - 1950)}

A migração para o oeste paranaense fez parte do fluxo migratório que aconteceu no Brasil no contexto do projeto de nacionalização das fronteiras, no período do Estado Novo (1937-1945). $\mathrm{Na}$ primeira metade do século $\mathrm{XX}$, a fronteira do oeste paranaense era uma região pouco desenvolvida se comparada ao restante do país. Devido à prática de concessão de terras, feita pelo governo estadual desde a segunda metade do século XIX, beneficiando grupos empresariais ligados ao governo, e as constantes renovações destas, a integração nacional da região foi duramente prejudicada (ANDRADE, 2018).

Nesse período, a economia da região estava alicerçada na exploração das riquezas naturais, especialmente da erva-mate e da madeira. Tanto os proprietários como os trabalhadores das terras eram, em sua maioria, estrangeiros. Tratava-se da extração e do comércio de produtos de origem agrícola em grandes propriedades, denominadas de obrages ${ }^{1}$. Esse tipo de exploração teve início no Oeste do Paraná no final do século XIX e se intensificou nas primeiras décadas do século XX. A erva-mate era um produto consumido em larga escala em toda América Latina. Depois de esgotar a extração do produto na Argentina, principal fornecedor de erva-mate para região, os obrageros ${ }^{2}$, passaram a ocupar as terras do oeste paranaense para extrair e comercializar o produto (GRONDIN, 2007; WACHOWICZ, 198).

Devido às consecutivas renovações de suas concessões, as obrages acabaram determinando a estrutura produtiva da região Oeste do Paraná por mais de cinquenta anos. No período, a educação escolar na região sofria com o pouco investimento do Poder Público, tinha apenas duas escolas no núcleo pioneiro, onde atualmente é o munícipio de Foz do Iguaçu, criadas em 1917, conforme consta da Lei Municipal n..$^{\circ}$ 024, de 07 de março de 1917 (FOZ DO IGUAÇU, 1917).

\footnotetext{
${ }^{1}$ As obrages nada mais foram do que imensos domínios rurais que se estabeleceram, primeiro no norte argentino e, posteriormente, no oeste do Paraná e na parte sul do Estado do Mato Grosso para a exploração da erva-mate e da madeira, empregando, geralmente, mão-de-obra paraguaia, denominada “mensus", em sistema de quase escravidão (GRONDIN, 2007, p. 41). Obrage: no Oeste do Paraná, surgiram, no fim do século passado e no início do século XX, gigantescas concessões por parte do governo paranaense para a exploração de erva-mate. Por extensão da terminologia adotada em território argentino, as mesmas propriedades ou concessões foram denominadas de obrages. Significa originalmente o local onde se trabalha manualmente (WACHOWICZ, 1982, p.182).

${ }^{2}$ Obragero: termo em espanhol utilizado para designar o proprietário ou dono da concessão denominada de obrage (WACHOWICZ, 1982, p.182).
} 
A partir do programa federal Marcha para o Oeste, criado pelo Governo Vargas no fim dos anos de 1930, o Oeste do Paraná passou por mudanças estruturais. O projeto de "nacionalização" e ocupação da região se intensificou durante a década de 1940. Com incentivo do governo federal e sob os auspícios do nacionalismo, especialmente a partir da segunda metade da década, a região da tríplice fronteira passou a receber grande contingente de migrantes, oriundos, especialmente dos estados de Santa Catarina e Rio Grande do Sul. Impelidos a migrar pelas novas condições sociais determinadas pelo estágio de desenvolvimento das forças produtivas, esses agricultores provenientes das antigas colônias de imigrantes italianos e alemães, radicaram-se no oeste paranaense e constituíram novos núcleos populacionais (GREGORY, 2005; PADIS, 1981; WACHOWICZ, 1982).

As várias fases de ocupação pelas quais a região passou, sempre estiveram alinhadas ao cenário nacional e internacional de desenvolvimento das forças produtivas e atendendo aos interesses de determinados grupos sociais. A educação escolar, por sua vez, não esteve desarticulada dessa conjuntura sociopolítica e econômica. O processo escolarização da região esteve intrinsicamente relacionado ao movimento migratório. Primeiramente foi criado um modelo educacional denominado de "instrução sem instituição", ou seja, havia iniciativas particulares de escolarização, mas não existia nenhuma escola ou Casa Escolar na região. Esse modelo de escolarização particular era realizado por uma pessoa do grupo social que apresentasse condições mínimas de ensinar as crianças a ler, escrever e calcular. Os objetivos dessa educação eram traçados pelos pais dos alunos (EMER, 2004).

Outra forma de educação escolar na região foi a Casa Escolar Particular. Essa modalidade de ensino se caracterizou como uma escola construída e mantida por um grupo de pioneiros. Não era oficial, porém, funcionava tecnicamente bem e o professor deveria ter melhor qualificação em relação ao primeiro modelo.

A Casa Escolar Pública foi outro modelo de educação que se consolidou, principalmente nos núcleos urbanos. Eram escolas oficializadas. O Poder Público viabilizava suas edificações e remunerava os professores. Os alunos eram submetidos a exames públicos para que confirmassem a escolarização realizada no nível do Ensino Primário e recebiam um certificado que "comprovava" o conhecimento. Esse modelo, de algum modo, constituía-se como um meio de divisão social do trabalho. Assim, a organização da escola passou a reproduzir a organização da sociedade no oeste paranaense (EMER, 1991). 
A partir das décadas de 1950/1960 houve um significativo avanço no processo de escolarização e na construção de escolas na região. A Escola Rural de Dois Irmãos foi criada nesse contexto de aumento da demanda por educação escolar.

\section{A educação rural no Brasil e no oeste paranaense}

A Escola Rural ganhou destaque no Brasil a partir da década de 1930 com a emergência de ideias ligadas à corrente de pensamento denominada de ruralismo pedagógico, cujos pressupostos centrais residiam na implantação de uma escola rural que considerasse as peculiaridades de cada região e deveria propiciar uma formação para o trabalho na terra, pois dela resultaria a subsistência para o homem do campo. O ruralismo pedagógico se constituiu num pensamento que privilegiava o papel da escola na construção de um homem novo, adaptado à nova realidade brasileira e de uma relação homem rural/escola pretensamente nova. Este ideário estava associado a uma ideia de que o valor da escola rural estava para além da ação educativa, ou seja, tinha a finalidade de realizar um trabalho cívico, patriótico e com fins econômicos (PRADO, 1995).

Na década de 1950, destacam-se a Campanha Nacional de Educação Rural (CNER) e o Serviço Social Rural (SSR), que desenvolveram projetos que visavam preparar professores com habilidades técnicas para educação rural e programas nas áreas de saúde, economia doméstica, artesanato e trabalho. Tanto a CNER como a SSR estavam a serviço de uma ideologia política que propunha a modernização do campo por meio de ações assistencialistas. Tais programas voltados para a educação rural receberam forte influência de modelos educacionais dos Estados Unidos da América, e tinham a intenção de integrar o camponês ao mercado de consumo. A origem desta vertente estava no pensamento empresarial que previa o assistencialismo e o controle político sobre a terra e sobre as pessoas que viviam e dependiam dela (DAMASCENO; BESERRA, 2004).

O ruralismo pedagógico que vigorou em muitas regiões do país nesse período, procurava oferecer respostas às tensões sociais que resultavam do êxodo rural e do inchaço das cidades, que por sua vez, não estavam preparadas para absorver a mão de obra disponível. A educação foi utilizada como subsidiária de uma ideologia, qual seja: fixar o homem no campo, por meio da adaptação de programas e currículos ao meio rural que reforçavam os valores camponeses (LEITE, 1999).

No período da migração para o Oeste do Paraná, a região era habitada principalmente por pessoas que viviam na área rural. Os migrantes que se estabeleciam na região, buscavam oportunidades para trabalhar na terra, para isso, compravam pequenos lotes rurais e desenvolviam a agricultura familiar. A escola constituía-se num fator importante para esses migrantes, pois atendia 
seus anseios de conceder aos próprios filhos a oportunidade da escolarização (ANDRADE, 2018). Foi nesse contexto de valorização da escola como elemento necessário para o desenvolvimento local, mediante o convênio celebrado entre o estado do Paraná e o Governo Municipal de Foz do Iguaçu, que a Escola Rural de Dois Irmãos foi criada.

\section{A implantação da Escola Rural de Dois Irmãos (1953-1959)}

Para a análise do nosso objeto, consideramos a orientação do Justino Pereira de Magalhães (2004), quando afirma que o desafio da pesquisa sobre a trajetória histórica de qualquer instituição educativa é integrá-la na realidade mais abrangente, que é o sistema educativo; contextualizá-la, implicando-a no quadro da evolução de uma comunidade e de uma região. Para tal, faz-se necessário, além de extrair e analisar elementos do interior da escola que ajudam a explicitar o movimento ali ocorrido, olhar também para o entorno, pois é por meio desta averiguação que elementos imperceptíveis vêm à tona, oferecendo evidências materiais dos impactos que a instituição produziu em seu público-alvo e, consequentemente, na sociedade onde desenvolveu e/ou desenvolve suas atividades.

A década de 1950, contexto da criação da Escola Rural de Dois Irmãos, aponta para um cenário político-educacional de transição nas várias esferas do país: política, economia e educação. No campo político, Getúlio Vargas (1882-1954) havia sido eleito Presidente da República em 1950, por meio do voto popular. A ênfase do Governo Vargas estava no progresso econômico brasileiro, que efetivaria por meio da expansão da indústria; do fortalecimento da burguesia nacional e da consolidação do capitalismo no país, que, à época, estava em franco processo de modernização. Essa visão de progresso intensificou as ondas migratórias do campo para as cidades, o que resultou num significativo aumento de trabalhadores nas cidades (ARNAUT DE TOLEDO; ANDRADE, 2012).

A partir da década de 1930, o Brasil iniciou um processo de profundas mudanças em sua estrutura social e econômica. Houve um efetivo avanço na industrialização e no desenvolvimento urbano do país. As mudanças desse período produziram uma reestruturação no sistema econômico, que passou de um modelo colonial primário para uma economia de mercado aberto (FAUSTO, 1995). O fortalecimento dessas novas forças sociais trouxe mudanças no aparelho estatal, com particular destaque para a criação de partidos políticos que pudessem atender aos interesses de seus grupos. Como exemplo podemos citar a União Democrática Nacional (UDN), fundada em 1945, organizado em meio aos debates que reivindicavam a redemocratização do país no período final do Estado Novo. Com propostas de feição claramente liberal, o partido 
representava os setores rurais e as camadas burguesas da sociedade. (ARNAUT DE TOLEDO, GARUTI DE ANDRADE, 2017).

Nesse mesmo contexto, em 1945, foi criado o Partido Social Democrático (PSD), por iniciativa de Getúlio Vargas e liderado por Eurico Gaspar Dutra (1883-1974). Após o suicídio de Vargas, o PSD elegeu Juscelino Kubitschek (1902-1976), Presidente da República com o apoio do Partido Trabalhista Brasileiro (PTB). Esse Partido, fundado em 1945, possuía características mais alinhadas à esquerda e defendia a intervenção do Estado na economia e na política social (SAVIANI, 2008).

A partir do momento em que Juscelino Kubitschek assumiu a Presidência, em 1956, o país passou a ser direcionado por uma ideologia que priorizava o desenvolvimento. A política econômica de Kubitschek foi delineada por um Plano de Metas que tinha como lema "cinquenta anos de progresso em cinco de governo". A aplicação do Plano resultou na expansão e na consolidação do capitalismo no Brasil (FAUSTO, 1995).

No campo educacional, a escola foi elevada há um lugar de destaque no processo de reconstrução da sociedade brasileira. Era defendida a necessidade de uma reorganização do ensino. A Escola Rural de Dois Irmãos foi criada nesse contexto de expansão do ensino primário para todas as localidades do país, com o incentivo governamental para a migração para regiões de fronteiras. A instituição iniciou suas atividades um ano após a emancipação política e administrativa de Toledo e foi uma das primeiras escolas do município. Segundo consta da ata exames finais do primeiro ano funcionamento da instituição, as atividades da Escola Rural de Dois Irmãos tiveram início em 14 de março de 1953 (ESCOLA RURAL DE DOIS IRMÃOS, 1953b).

Considerando esse contexto geral, pode-se afirmar que a instituição foi criada para atender aos interesses governamentais que, naquele período, pretendia, além de resolver o problema educacional dos moradores daquela localidade, marcar presença em uma região estratégica do ponto de vista político e econômico.

A seguir, será realizada a análise da organização pedagógica da Escola Rural de Dois Irmãos, que contemplará os seguintes elementos: corpo discente e o corpo docente. O estudo desses aspectos da instituição contribui para a análise de sua história e papéis que desempenhou naquela sociedade.

\section{Docentes e discentes}

O primeiro professor da Escola Rural de Dois Irmãos foi Armindo José Michels, que trabalhou na instituição por um período de sete anos, de 1953 a 1959, como seu único docente. 
Embora a escola tenha iniciado suas atividades sob a direção do município, eram os pais dos alunos que pagavam os honorários do professor, pois viam a educação escolar como necessária para o futuro de seus filhos e da própria comunidade (ESCOLA RURAL DE DOIS IRMÃOS, 1954).

Consta da ata de exames finais do ano de 1953, que a educação desenvolvida pela Escola Rural de Dois Irmãos era de qualidade, devido, sobretudo, ao empenho do professor, que recebeu elogios da comissão responsável pela aplicação dos Exames. A Comissão destacou que estava "impressionada com a ordem reinante na escola e com o aproveitamento satisfatório dos alunos. [...] deixa consignado na presente Ata, um voto de louvor ao professor Armindo José Michels" (ESCOLA RURAL DE DOIS IRMÃOS, 1953b).

Os primeiros alunos da escola eram os filhos dos trabalhadores rurais recém chegados ao vilarejo de Dois Irmãos. Em seu primeiro ano de funcionamento, conforme consta da ata de fundação, de 23 de março de 1953, a escola contou com o total de 11 alunos, sendo 05 meninas e 06 meninos, todos moradores da comunidade local (ESCOLA RURAL DE DOIS IRMÃOS, 1953a).

A atividade econômica dos pais dos primeiros alunos da Escola Rural de Dois Irmãos estava associada ao cultivo da terra, à pecuária e, sobretudo, à policultura. A profissão dos pais dos alunos que frequentaram a instituição pode ser assim relacionada: agricultores (pequenos proprietários de terras); pequenos comerciantes (donos de serrarias e mercearias); profissionais liberais (mecânicos, carpinteiros, marceneiros); entre outros. A seguir, apresentamos uma fotografia da primeira turma de alunos da Escola Rural de Dois Irmãos, acompanhados pelo professor Armindo José Michels: 


\section{Dialogia}

ANDRADE, Rodrigo Pinto de; TOLEDO, Cézar de Alencar Arnaut de; ANDRADE, Francielle Aparecida

Garuti de. História da Educação na região Oeste do Paraná: a implantação da Escola Rural de Dois Irmãos (1953-1959)

Figura 1: Foto da primeira turma da Escola Rural de Dois Irmãos, 1953.

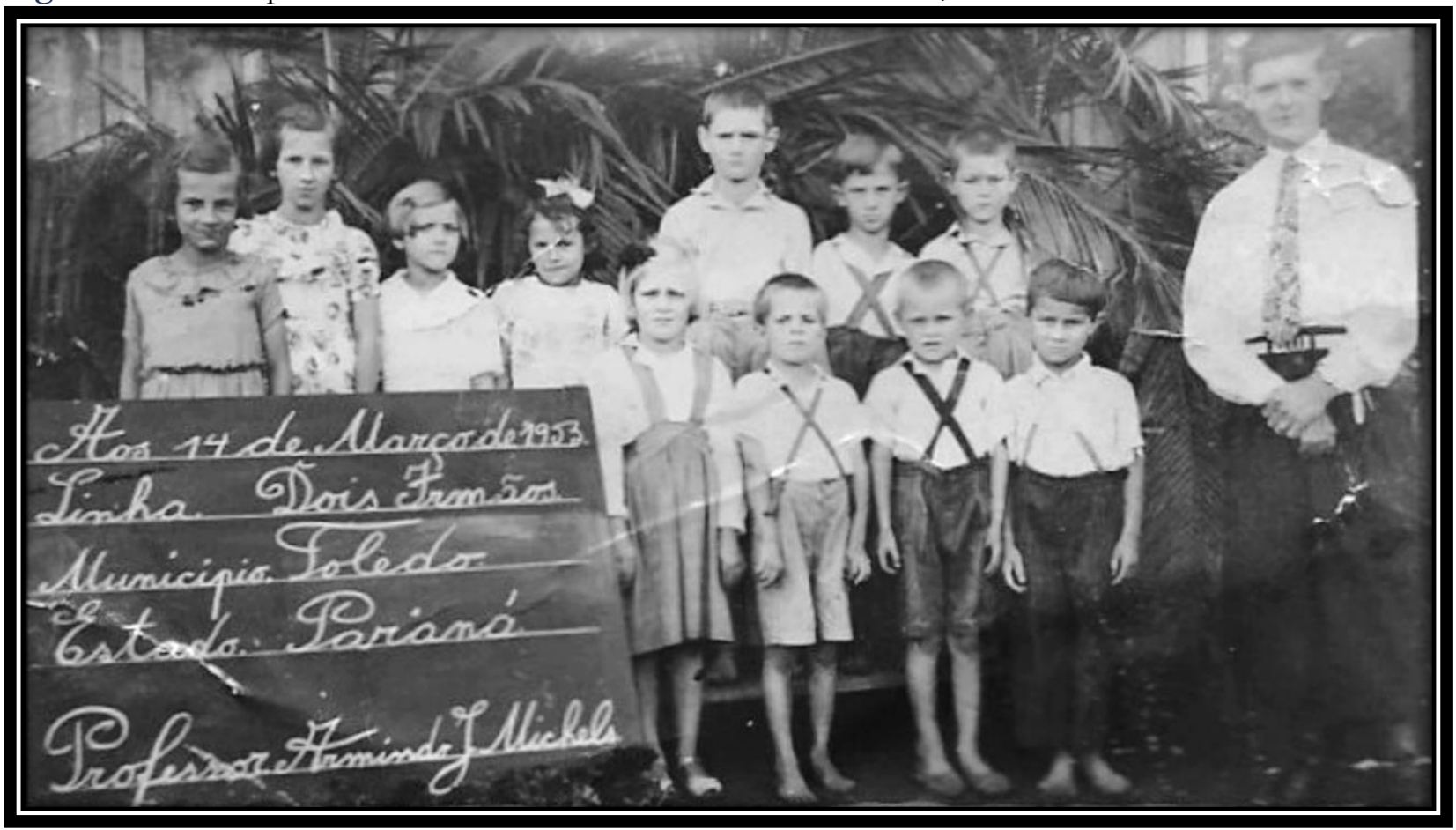

Fonte: Acervo do Museu Histórico Willy Barth, de Toledo, PR.

Os alunos que compuseram a primeira turma da Escola Rural de Dois Irmãos, conforme consta da documentação disponível nos acervos da instituição, foram: Alaíde Kunkel; Albino Finkler; Cassiano Thomas; Edmundo Hann; Erna Finkler; Feliciano Finkler; Flávio Scherer; Inês Scherer; Ivo Ottmar Haab; Odilo Scherer; Wilibardo Finkler (ESCOLA RURAL DE DOIS IRMÃOS, 1953b).

Na percepção de Ester Buffa, a análise da composição do corpo discente de uma instituição escolar pode ser um ponto importante para a compreensão de sua relevância social, bem como, de sua proposta educacional. $\mathrm{O}$ destino profissional que seus ex-alunos traçaram pode servir de subsídio no processo de apreensão do formato de educação escolar que a instituição desenvolveu (BUFFA, 2007).

Em nossa análise do quadro de ex-alunos da Escola Rural de Dois Irmãos, verificamos que muitos dos discentes que fizeram parte da primeira turma vieram a desenvolver funções sociais de destaque na sociedade de Toledo, ocupando cargos de relevância política e religiosa no oeste paranaense e até mesmo em nível nacional, como é o caso do Cardeal Arcebispo da Arquidiocese de São Paulo, Dom Odilo Scherer.

O quadro abaixo foi elaborado com base nos dados dos livros-ata de exames finais da Escola Rural de Dois Irmãos, dos anos de: 1953; 1954; 1955; 1956; 1957; 1958 e 1959. O quadro de alunos da escola pode ser assim descrito. 
ANDRADE, Rodrigo Pinto de; TOLEDO, Cézar de Alencar Arnaut de; ANDRADE, Francielle Aparecida Garuti de. História da Educação na região Oeste do Paraná: a implantação da Escola Rural de Dois Irmãos (1953-1959)

Quadro 1 - Turmas da Escola Rural de Dois Irmãos (1953 a 1959)

\begin{tabular}{|l|l|l|l|}
\hline Ano & Alunos aprovados & Alunos reprovados & Total de alunos \\
\hline 1953 & 11 & 00 & 11 \\
\hline 1954 & 21 & 00 & 21 \\
\hline 1955 & 23 & 11 & 34 \\
\hline 1956 & 30 & 09 & 39 \\
\hline 1957 & 19 & 05 & 24 \\
\hline 1958 & 19 & 06 & 25 \\
\hline 1959 & 16 & 09 & 25 \\
\hline
\end{tabular}

Fonte: (TOLEDO, 1955); (TOLEDO, 1956); (TOLEDO, 1957); (TOLEDO, 1958).

Em 1959, o número de alunos matriculados foi de 25, no ano subsequente, as matrículas aumentaram exponencialmente, o número de discentes passou para 163. O motivo de um aumento tão significativo pode ser explicado pela ampliação do nível de ensino, pois a escola passou a receber maior aporte financeiro da Secretária Municipal de Educação e começou a ofertar também, outras modalidades de ensino. A partir dessa data, a instituição passou a adotar o nome de Escola Rural Municipal Princesa Isabel (ESCOLA RURAL DE DOIS IRMÃOS, 1960).

\section{Conclusão}

A análise dos dados revelados pelas fontes indica que a história da instalação da Escola Rural de Dois Irmãos esteve diretamente relacionada com o processo de migração e escolarização do oeste paranaense e do município de Toledo. Foi uma das primeiras escolas da região, formada um ano após ser criado o município. A instituição foi criada para atender aos filhos dos trabalhadores rurais que residiam naquela localidade e contribuiu para a formação de uma cultura letrada na região.

O estabelecimento de uma instituição educativa foi pensado quatro anos depois da chegada dos primeiros colonos à região. A primeira leva de migrantes chegou à localidade de Dois Irmãos no ano de 1949 e a escola foi construída em 1953. A maioria desses agricultores vinha de regiões onde não tinham acesso à escola, por isso, após sua instalação na localidade para a qual migraram, decidiram reivindicar e investir na educação escolar, pois a enxergavam como uma possibilidade de ascensão social. Em suas regiões de origem, os migrantes eram impossibilitados do acesso à escola, ao se estabelecerem no oeste paranaense, viram nessa nova realidade geográfica a materialização dessa possibilidade e por isso, apostaram na educação escolar e reafirmaram a ideia que não se pode ter "uma comunidade sem escola". 
Podemos dizer que as atividades da Escola Rural de Dois Irmãos estiveram alinhadas ao projeto de nacionalização da educação que vigorou no Brasil durante as décadas de 1930 a 1950. Essas medidas de nacionalização da educação foram coerentes com o cenário político, econômico e social que imperava no país naquele momento, ajustado ao contexto internacional adequado a este ideário.

Assim sendo, é possível afirmar que essa instituição educativa, mesmo que de maneira indireta, cumpriu o papel de consolidar o discurso do Governo Federal de valorização da educação como meio de ascensão social, expressa no processo de urbanização do país. Suas práticas educativas não destoaram das políticas educacionais vigentes no período e acabaram atendendo às demandas educativas daquela sociedade, servindo ao propósito de formar trabalhadores que contribuíram com o avanço do capitalismo numa região de colonização recente.

Salientamos que este texto contribui com o trabalho de reconstituição da história e da memória da educação e das instituições educacionais na região Oeste do Paraná. Essa tarefa tem representado um desafio aos pesquisadores na área de História da Educação, pois as fontes para realização de tais investigações, em sua maioria, já se perderam ou estão se perdendo. Parte da documentação ainda se encontra dispersa e sem o acondicionamento adequado. Evidencia-se, portanto, que se faz urgente e necessário o trabalho de levantar e catalogar as fontes sobre o processo de escolarização desta região de colonização recente, para tal, há que envidar esforços acadêmicos e os necessários aportes de recursos no sentido de reconstituir a história e a memória das instituições educativas regionais.

\section{Referências}

ANDRADE, Rodrigo Pinto de. Religião e educaşão escolar na colonização do oeste paranaense: o caso da implantação do Colégio Vicentino Incomar, de Toledo (1948-1965). Curitiba: CRV, 2018.

ARNAUT DE TOLEDO, Cézar de Alencar; ANDRADE, Rodrigo Pinto de. História da implantação da Escola de Porto Britânia no contexto da colonização do oeste paranaense (19381958). EccoS, São Paulo, n. 29, p. 199-217. set./dez. 2012.

ARNAUT DE TOLEDO, Cézar de Alencar; GARUTI DE ANDRADE, Francielle Aparecida. História da implantação da Escola Rural de Xaxim (1952-1961) no contexto da escolarização do oeste Paranaense. Quaestio, Sorocaba, SP, v. 19, n. 1, p. 47-68, abr. 2017.

BUFFA, Ester. Os estudos Sobre Instituições Escolares: organização do espaço e propostas pedagógicas. In: NASCIMENTO, Maria Isabel Moura; SANDANO, Wilson; LOMBARDI, José Claudinei; SAVIANI, Dermerval (org.). Instituições Escolares no Brasil: conceito e reconstrução histórica. Campinas: Autores Associados, 2007. p. 151-164. 


\section{Dialogia}

ANDRADE, Rodrigo Pinto de; TOLEDO, Cézar de Alencar Arnaut de; ANDRADE, Francielle Aparecida Garuti de. História da Educação na região Oeste do Paraná: a implantação da Escola Rural de Dois Irmãos (1953-1959)

DAMASCENO, Maria Nobre; BESERRA, Bernadete. Estudos sobre educação rural no Brasil: estado da arte e perspectivas. Educação e Pesquisa, São Paulo, v. 30, n. 1, p. 73-89, jan./abr. 2004. Disponível em: <file:///C:/Users/RODRIGO/Desktop/Educa\%C3\%A7\%C3\%A3o\%20Rural.pdf>. Acesso em: 6 abr. 2015.

ESCOLA RURAL DE DOIS IRMÃOS. Livro-ata: fundação Escola Rural de Dois Irmãos. Toledo: [Arquivo da Escola Rural Municipal Princesa Isabel] 1953a. $01 \mathrm{fl.}$

ESCOLA RURAL DE DOIS IRMÃOS. Livro-ata: exames finais do ano letivo de 1953 da Escola Rural de Dois Irmãos. Toledo: [Arquivo da Escola Rural Municipal Princesa Isabel] 1953b. $01 \mathrm{fl}$.

ESCOLA RURAL DE DOIS IRMÃOS. Livro-ata: exames finais do ano letivo de 1954 da Escola Rural de Dois Irmãos. Toledo: [Arquivo da Escola Rural Municipal Princesa Isabel] 1954. $01 \mathrm{fl.}$

ESCOLA RURAL DE DOIS IRMÃOS. Livro-ata: exames finais do ano letivo de 1955 da Escola Rural de Dois Irmãos. Toledo: [Arquivo da Escola Rural Municipal Princesa Isabel] 1955. $01 \mathrm{fl}$.

ESCOLA RURAL DE DOIS IRMÃOS. Livro-ata: exames finais do ano letivo de 1956 da Escola Rural de Dois Irmãos. Toledo: [Arquivo da Escola Rural Municipal Princesa Isabel] 1956. $01 \mathrm{fl.}$

ESCOLA RURAL DE DOIS IRMÃOS. Livro-ata: exames finais do ano letivo de 1957 da Escola Rural de Dois Irmãos. Toledo: [Arquivo da Escola Rural Municipal Princesa Isabel] 1957. 02 fl.

ESCOLA RURAL DE DOIS IRMÃOS. Livro-ata: exames finais do ano letivo de 1958 da Escola Rural de Dois Irmãos. Toledo: [Arquivo da Escola Rural Municipal Princesa Isabel] 1958. 02 fl.

ESCOLA RURAL MUNICIPAL PRINCESA ISABEL. Livro-ata: exames finais do ano letivo de 1960 da Escola Rural Municipal Princesa Isabel. Toledo: [Arquivo da Escola Rural Municipal Princesa Isabel] 1960. 03 fl.

EMER, Ivo Oss. Desenvolvimento histórico do oeste do Paraná e a construção da escola. 1991. 340f. Dissertação (Mestrado em Educação). Programa de Pós-Graduação em Educação, Fundação Getúlio Vargas, Rio de Janeiro, 1991.

EMER, Ivo Oss. Aspectos históricos da educaşão regional. Cascavel: Mímeo 2004.

FAUSTO, Bóris. História do Brasil. 2 ed. Editora da Universidade de São Paulo: Fundação do Desenvolvimento da Educação. São Paulo, 1995.

FOZ DO IGUAÇU. Lei Municipal n. ${ }^{\circ}$ 024, de 07 mar. 1917. Cria duas escolas municipais do sexo masculino.

GREGORY, Valdir. Os Eurobrasileiros e o Espaço Colonial: migrações no oeste paranaense. Cascavel: EDUNIOESTE, 2005.

GRONDIN, Marcelo. Alvorecer de Toledo, na colonização do Oeste do Paraná-1946 - 49. Marechal Cândido Rondon: Editora Germânica, 2007.

LEITE, Sérgio Celani. Escola rural: urbanização e políticas educacionais. São Paulo: Cortez, 1999. 
ANDRADE, Rodrigo Pinto de; TOLEDO, Cézar de Alencar Arnaut de; ANDRADE, Francielle Aparecida Garuti de. História da Educação na região Oeste do Paraná: a implantação da Escola Rural de Dois Irmãos (1953-1959)

MAGALHÃES, Justino Pereira de. Tecendo Nexos: história das instituições educativas. Bragança Paulista: EDUSF, 2004.

MAGALHÃES, Justino Pereira de. Contributo para a História das Instituições Educativas: Entre a Memória e o Arquivo. Braga, Universidade do Minho, 1999.

MAGALHÃES, Justino Pereira de. Um apontamento metodológico sobre a história das instituições educativas. In: SOUSA, Cunthia Pereira de; CATANI, Denice Bárbara. (Org.). Práticas educativas, culturas escolares, profissão docente. São Paulo: Escrituras Editora, 1998.

NOSELLA, Paolo; BUFFA, Ester. Instituições escolares: por que e como pesquisar. Campinas: Alínea, 2009.

PADIS, Pedro. Formação de uma economia periférica: o caso do Paraná. São Paulo: Hucitec, 1981.

PRADO, Adonia Antunes. Ruralismo pedagógico no Brasil do Estado Novo. Estudos Sociedade e Agricultura, Rio de Janeiro, n. 4, p. 5-27, 1995.

SANFELICE, José Luís. História das Instituições Escolares. In: NASCIMENTO, Maria Isabel Moura: SANDANO, Wilson; LOMBARDI, José Claudinei; SAVIANI, Dermeval (Org.). Instituições Escolares no Brasil: conceito e reconstrução histórica. Campinas: Autores Associados, 2007. p. 75-93.

SAVIANI, Dermeval. Instituições de memória e organização de acervos para a história das instituições escolares. In: SILVA, João Carlos da; ORSO, José Paulino; CASTANHA, André Paulo; MAGALHÃES, Lívia Diana Rocha. (Org.). História da educação: arquivos, instituições escolares e memória histórica. Campinas: Alínea, 2013. p.13-31.

SAVIANI, Dermeval. História das Ideias Pedagógicas no Brasil. 2. Ed. rev. e ampl. Campinas: Autores Associados, 2008.

SAVIANI, Dermeval. Instituições Escolares no Brasil Conceito e Reconstrução Histórica. In: NASCIMENTO, Maria Isabel Moura; SANDANO, Wilson; LOMBARDI, José Claudinei; SAVIANI, Dermeval (Org.). Instituições Escolares no Brasil: conceito e reconstrução histórica. Campinas: Autores Associados, 2007. p. 03-27.

TOLEDO. Decreto n 434, de 08 de novembro de 2010. Diário Oficial [do] Município de Toledo. Toledo, 08 de novembro de 2010.

TOLEDO. Secretaria Municipal de Educação. Portaria n 53/2011 de 20 de junho de 2011. Toledo: SMED, 2011. $02 \mathrm{f}$.

TOLEDO. Secretaria Municipal de Educação. Relatório da Secretaria Municipal de Educação sobre a construção do prédio próprio da Escola Rural de Dois Irmãos. Toledo: SMED, 1957. 03 f.

WACHOWICZ, Ruy. Obrageros, mensus e colonos: história do oeste paranaense. Curitiba: Vicentina, 1982. 